\title{
Personalized safety route recommender application using integrated urban crime hotspot data
}

\section{Atut Pindarwati, Arie Wahyu Wijayanto}

Atut Pindarwati, Arie Wahyu Wijayanto, "Personalized safety route recommender application using integrated urban crime hotspot data," Proc. SPIE 11311, Sixth Geoinformation Science Symposium, 1131105 (21 November 2019); doi: 10.1117/12.2547331

EDIE Event: Sixth Geoinformation Science Symposium, 2019, Yogyakarta, Indonesia 


\title{
Personalized Safety Route Recommender Application using Integrated Urban Crime Hotspot Data
}

\author{
Atut Pindarwati*a ${ }^{*}$ Arie Wahyu Wijayanto ${ }^{\mathrm{a}}$ \\ ${ }^{a}$ BPS-Statistics Indonesia, Jakarta, Indonesia \\ Corresponding author's email: atutpindarwati.95@gmail.com
}

\begin{abstract}
In a modern urban society with a high demand for mobilization, location-based personal navigation service plays a fundamental role in daily activities. With the help of real-time and accessible GPS technology, online navigation service such as Google Map and Street View have become more important and increasingly popular. Being designed for simplicity and scalability, most of these current service will suggest routes based on the fastest travel time or the shortest distance to a destination. However, in developing countries such as Indonesia, which is still struggling with crime rate issue, the requirement for safety become an undoubtedly crucial factor for human mobility. In this paper, we propose an integrated web-based system using the crime hotspot area based on crime history from the local government agency, existing geotagged social media crime news and user reported data. The users could further involve and contribute by reporting their personal safety experience to increase the recommendation accuracy in the future. Build on the free and opensource GraphHopper Routing API, our proposed personalized user feature also include rerouting option and crime contour map. We focus on Jakarta area as our case study, which served as the heart of citizen activity in Indonesia. The key result of the proposed framework is a personal navigation map that recommends the safest route to the user which bypass potenti al crime-prone areas.
\end{abstract}

Keywords: Navigation Service, Route Recommender, Crime Prevention, Web-based GIS, Crime Mapping

\section{INTRODUCTION}

Transportation has been considered as one of the most essential aspects of daily urban life in many developing countries. It also known to have a direct influence on the national economic growth ${ }^{1}$. Daily commuting is part of the most common transportation activity for the urban citizen. With the growing demand for commuting activity, online applications could assist the transportation activities to become popular ${ }^{2}$. In the second quarter of 2019, Google Maps application has been downloaded by more than 5 billion times by android user only ${ }^{3}$. Online map and navigation applications such as Google Maps and Waze could provide the best route recommendation according to the user mode of transport. The application would gather information from the internet, and with its complicated algorithm, it is capable to recommend the fastest route. Some of the application even provides the estimation arrival time from several route alternatives.

However, the fastest route option may not always the preferred route by the user. Other factors influence the route selection process by the commuter, such as the comfort issue and the safety issue. The comfort issue could be from the road condition, supporting facilities along the road, or even the scenery while the safety issues mostly related to the possibility of criminality incident befall during the travel on the suggested route. For instance, some women would prefer to change their route to avoid the possibility of harassment and unwanted assault. According to the BPS-Statistics Indonesia, there were 352.936 criminal case and 140 threat of risk for the people due to the criminal case in $2015^{4}$. Levy, Belding and Wang ${ }^{16}$ introduced three component to decrease criminal case by analyzing crime, input different types information, allow human feedback with policy updates ${ }^{16}$

In this paper, we propose an alternative solution to answer the traveling safety concern which was not yet accommodated by the existing route recommendation algorithm of the currently popular navigation service. The currently available service to accommodate the user personalized safety concern relies on two essential methods. The first method, called as the map rerouting, in which the users may create their own route manually to avoid a particular area that they believe as unsafe. This method is beneficial for users in the area that they are familiar with. However, it will be quite troublesome in the unknown area and for uninformed beginner level users. In the second method, which popularly known as the contour map, the historical crime records are plotted on the map and visualized in the form of a criminal case contoured

Sixth Geoinformation Science Symposium, edited by Sandy Budi Wibowo, Andi B. Rimba

Stuart Phinn, Ammar A. Aziz, Proc. of SPIE, Vol. 11311, 1131105 - C 2019 SPIE

CCC code: $0277-786 \mathrm{X} / 19 / \$ 21 \cdot$ doi: $10.1117 / 12.2547331$ 
map. The user would get visual information of the safe zone and crime hotspot zone. Both of those methods, despite their useful properties, are still lack of providing solid recommendation for most of the users. In contrast, we propose to provide automatic route recommendation based by blocking the potentially crime-prone area.

\section{RELATED WORKS}

\subsection{Crime Mapping}

Numerous studies have been introduced to investigate the solution of criminal behavior in modern society ${ }^{5,6}$. Crime mapping is an essential requirement to build a safer community. With the crime maps, the authority could prepare the appropriate preventive action to improve the safety of each area.Crime maps could records of crime incidents as well from OpenStreetMaps ${ }^{17}$. Brantingham and Brantingham ${ }^{7}$ introduced the Location Quotients, Counts, and Rates as the parameters to analyze and map the high-crime area in British Columbia. The variable "Counts" and "Rates" are common in the conventional crime report of a specific location. However, the variable "Location Quotients" give a pattern perspective of crime activity in a specified location. Therefore, each area will have a different characteristic of crime risk. Visualization is essential to make the crime risk characteristic of a region more comfortable to understand. Domino Project ${ }^{8}$ used Python programming to maps the crime-prone area in San Francisco. This project showcased the use of Folium Library in Python to create map visualization. Kahle and Wickham ${ }^{9}$ used the R programming language to create a contour map of the high-crime region in Houston. They combine ggplot2 and Google Maps to create spatial visualization using $\mathrm{R}$ language.

\subsection{Online Map and Navigation Application}

In the current digital era, the development of map and navigation applications have become inevitably popular. In early 2000, White et al ${ }^{10}$ develop a map matching algorithm for the 3rd generation Personal Navigation Assistant (PNA). The map matching algorithm searches the location/coordinate that is inputted by the user in the prepared maps' database. The development of map and navigation application at that time is far less sophisticated compared to the current system.

Steinmann et $\mathrm{al}^{11}$ brought up public participation in online maps development. In 2005, the two ways of communication between online application developers and the users were becoming possible to exist. However, there was no available technology that readily available to support that function. In 2013, Hu \& $\mathrm{Dai}^{13}$ discussed the fast development of online map applications. Spatial data from many sources have been integrated to provide more specific service. It could be observed from the usage of Application Programming Interface (API) to make the application became more intuitive and gave an option for the user to input data to the application. Those input data through API were recorded and processed to develop and update the online maps.

\section{METHODOLOGY}

\subsection{Route Calculation}

The route calculation method is the principal element of the route determination in any navigation applications. The route calculation method computes the original coordinates as the first location and destination as the second location using search function in the road network. The search function involves various decisions such as the distance of each segment that must be passed, signs, and boundaries associated with each segment. With specific algorithms, the optimum route is then selected. In general, the reference in determining the optimum route is travel time. However, the calculation of travel routes also provides a variety of alternative routes for users of map and navigation applications ${ }^{12}$. 


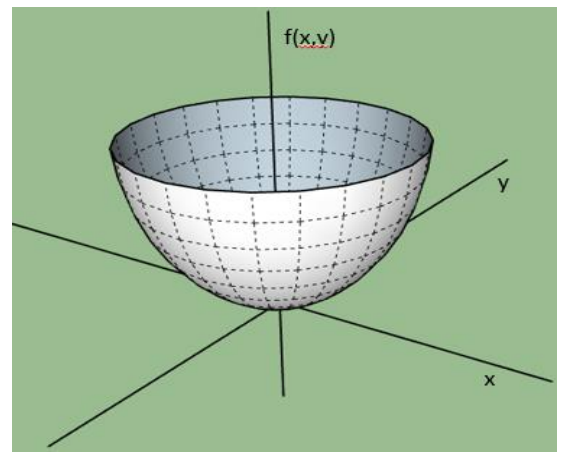

Figure 1. Paraboloid ${ }^{13}$

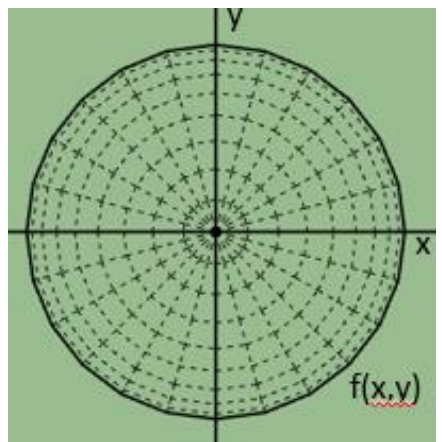

Figure 2. Contour Map Function ${ }^{13} \mathrm{f}(\mathrm{x}, \mathrm{y})$

Contour Map is a description of a function that has 2-dimensional input with 1-dimensional output ${ }^{13}$. For example a function $\mathrm{fx}, \mathrm{y}=3 \mathrm{x}^{2}+3 \mathrm{y}^{2}$ produce a 3-dimensional graph of a paraboloid, as shown in Figure 1 and Figure 2. Each connected line is called a contour line, and each contour line represents a value. Each point in a contour line has the same value. Application of contour maps in crime set a value that represents the crime rate at each point representing an administrative area. The assessment can be in the form of the accumulated intensity of crime cases accompanied by the weight of each case points with the same level of a crime connected to one line. Points between the two crime rate values are interpolated to get an estimate of the value of crime rates in the area.

\subsection{Comparison of Existing Crime Avoiding Methods}

At present, two methods are widely known in the existing map and navigation applications that can be used to avoid crime-prone areas. Those methods are called as Rerouting and Contour Map, as shown in Table 3. With the rerouting method, users will get the road route recommendations, along with estimated time based on map and navigation applications. The next step, users change the route to avoid areas prone to crime. This method provides flexibility for users to choose the path. However, this method reduces the efficiency of the path recommendations offered by the application. The second method is the Contour Map Crime. Some administrative regions have maps of crime vulnerability. The map can provide information about the area that needs to avoid. However, the map has a weakness in the form of generalization of the cumulative crime in a region. However, both of those methods, despite their useful properties, are still lack of providing automatic recommendation to ease the user when interacting with the application regarding the concern of safety route issue.

Table 3. Comparison of Each Methods

\begin{tabular}{|l|l|l|}
\hline \multicolumn{1}{|c|}{ Methods } & \multicolumn{1}{c|}{ Advantages } & \multicolumn{1}{c|}{ Disadvantages } \\
\hline Rerouting & $\begin{array}{l}\text { 1. Users get the flexibility to move the } \\
\text { destination point and choose manually } \\
\text { 2. There is an estimated time and distance } \\
\text { traveled by the user to the destination } \\
\text { 3. Users get recommendations for travel } \\
\text { routes }\end{array}$ & $\begin{array}{l}\text { Absence of additional supporting } \\
\text { information }\end{array}$ \\
\hline Contour map & $\begin{array}{l}\text { Users get information areas prone to crime } \\
\text { easily }\end{array}$ & $\begin{array}{l}\text { 1. Only the form of information, there } \\
\text { is no recommendation inside } \\
\text { Generalization of the cumulative } \\
\text { crime in area }\end{array}$ \\
\hline
\end{tabular}

\subsection{Proposed Framework}

Instead of limiting our framework to the existing methods, we propose to provide automatic route recommendation based by blocking the potentially crime hotspot area. To determine the crime hotspot area, we refer to the historical crime data from the local government agency, existing geotagged social media crime news and user reported data. DKI Jakarta Provincial Government published the crime and assault record data ${ }^{14}$. In this dataset, each historical crime data consist of the following information: 

i) district where the incident occur,
ii) type of crime activity, and
iii) count of the crime activity.

The social media such as Twitter and Instagram also provide a geo tagging feature that is also commonly use to report the incident case, including the crime activity. The geo tagging crime report using social media is accessible by public and become one of the source of information. This application also provide a platform for the users to further involve and contribute by reporting their personal safety experience to increase the recommendation accuracy in the future. Based on these data, crime hotspot area is mapped as a contour map. The accident coordinate of each crime per type are counted and mapped as crime-prone area contour map. The map shows the crime level of the region from a certain type of crime activity.

Build on the free and opensource GraphHopper Routing API ${ }^{15}$, our proposed framework uses the route selection mechanism based on the blocking and unblocking feature. The blocking feature will put the crime hotspot coordinate as restricted point and notify the route selection algorithm to avoid that area. Our proposed personalized user feature empower the users inputted information such as reporting a new crime based on their personal experiences. The detailed propose use case diagram of user involvement is shown in Figure 3. We focus on Jakarta area as our case study, which served as the heart of citizen activity in Indonesia.

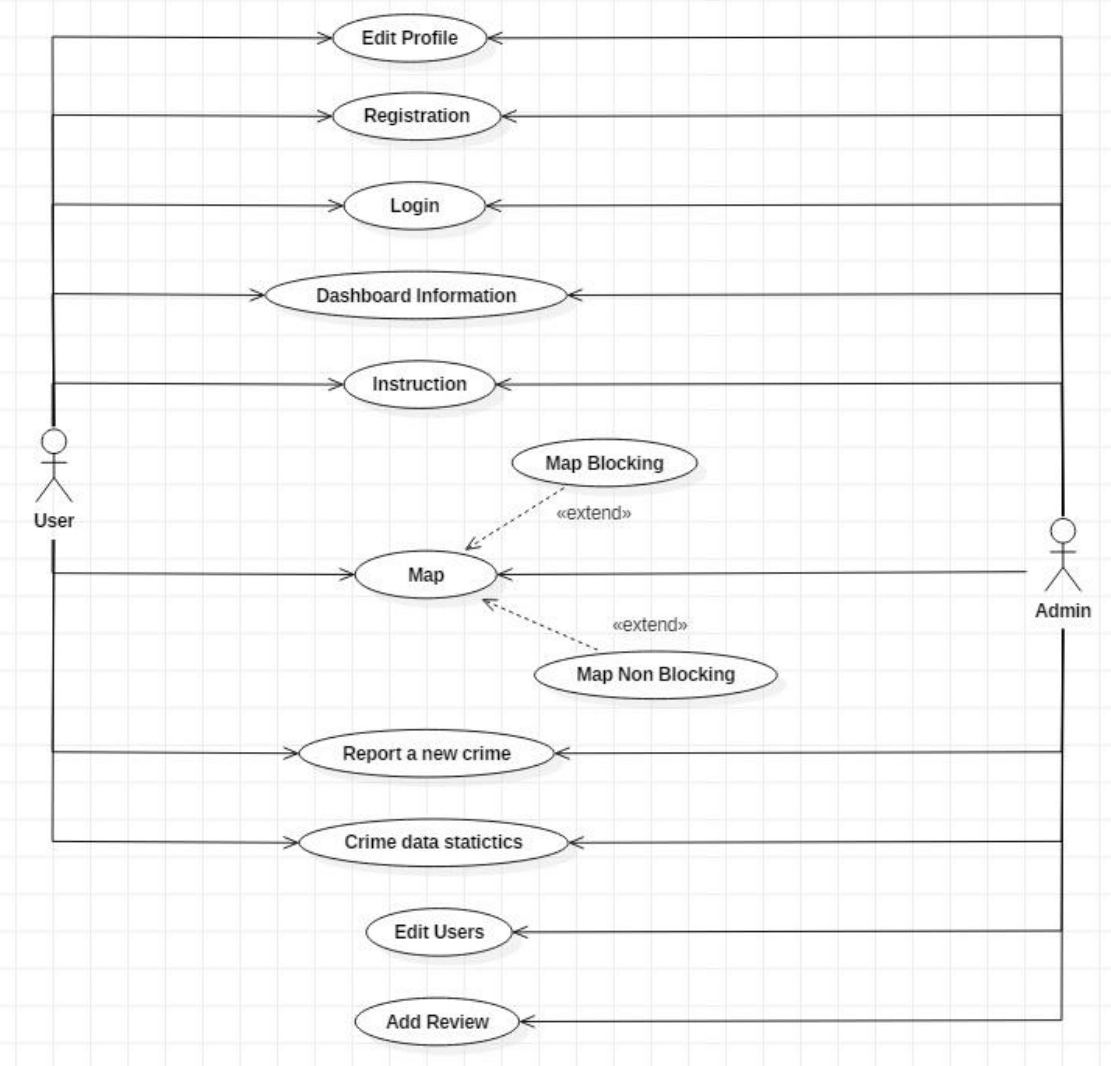

Figure 3. Proposed Use Case Diagram of User Involvement in Our Framework

\section{Automatic Route Selection based on Crime Area Blocking}

\section{Start}

2. Initialization of Application Data from database:

crime_name, location, coordinate1, coordinate2, sub_district, province, number_of_reports, 


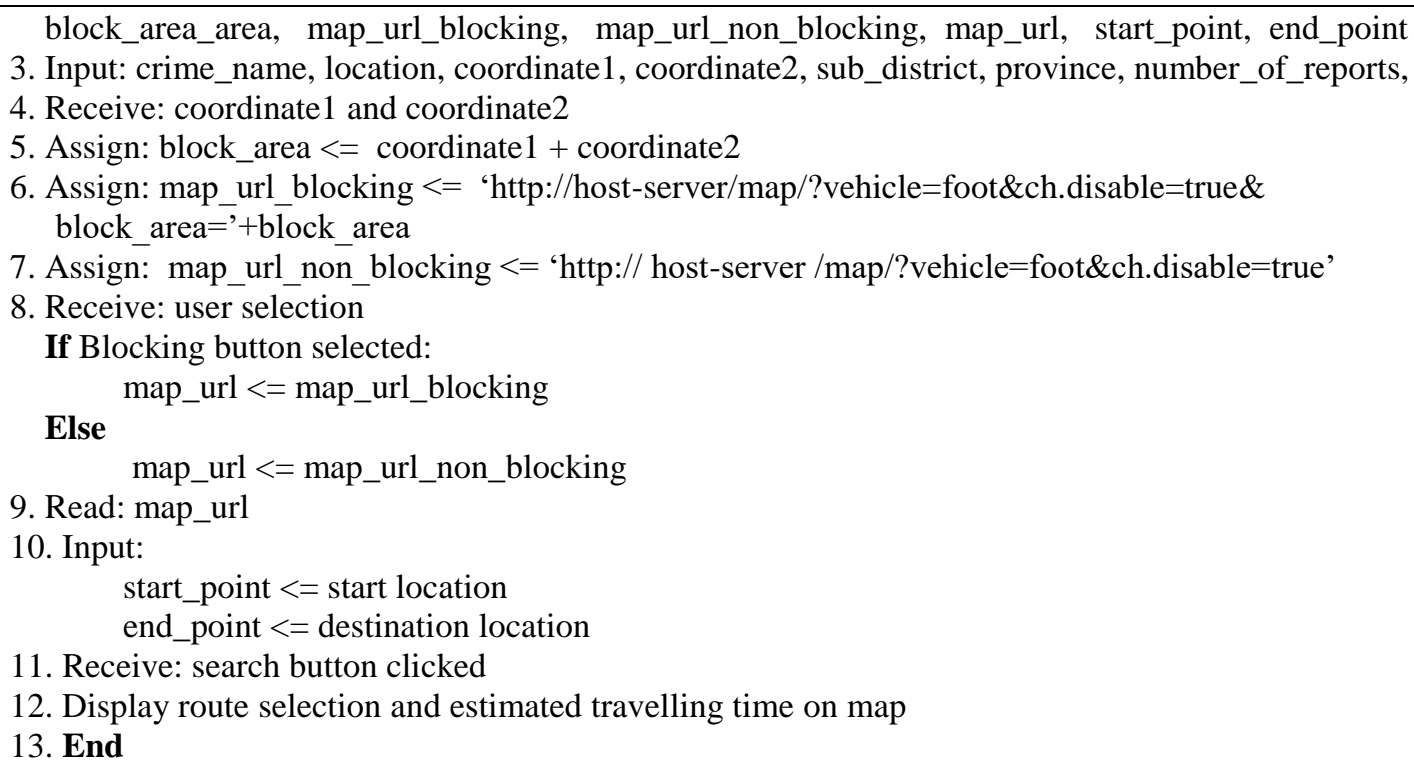

11. Receive: search button clicked

12. Display route selection and estimated travelling time on map

13. End

Algorithm 1. Automatic Route Selection based on Crime Area Blocking

Algorithm 1 illustrates the automatic route selection based on crime area blocking. The historical crime data and user reported information are stored in the database which further being used to assign the crime hotspot area. The area will then be automatically avoided under blocking feature. The user will receive the estimated travelling time and the recommended route which minimize the path through crime-prone locations.

\section{RESULT AND DISCUSSION}

In this section, we report the resulted framework implementation and discuss some key insight. In the following, we categorize the available features in our framework and their correlation to personal user safety recommendation.

\subsection{Statistics of Crime Historical Data}

We use the crime hotspot area based on crime history from the local government agency, existing geotagged social medeported data. The users could further involve and contribute by reporting their personal safety experience to increase the recommendation accuracy in the future. The view of crime historical data are only accesible and editable by administrator. The following are the user interface of the proposed framework. 


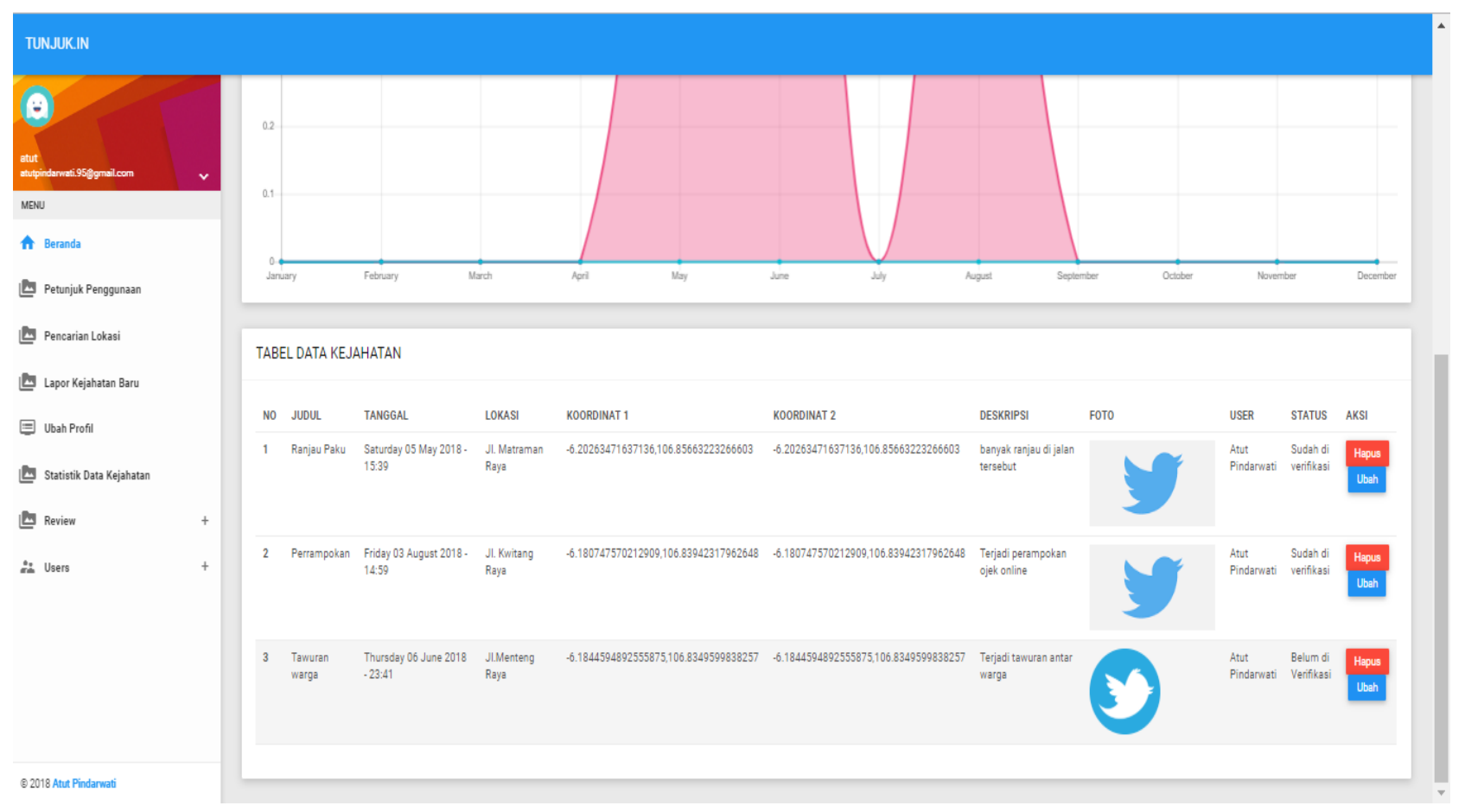

Figure 4. Example of the crime historical data and user reported data

As can be seen In Figure 4, there were coordinate1 and coordinate2 as located crime prone areas. After get validation from administrator, we will know about crime prone areas and it is automatically finding route to avoid crime prone areas. The results is recommended routes blocking area.

\subsection{Regular Routes without Area Blocking Feature}

By default, the user are able to determine whether the crime hotspot are blocking feature will be used or not. If the blocking feature is not selected by user, our framework will display the regular route based on the fastest estimated travelling time. User will receive the route and its detailed step-by-step navigation equipped with the estimated distance and travelling time for each step as shown in Figure 5. 


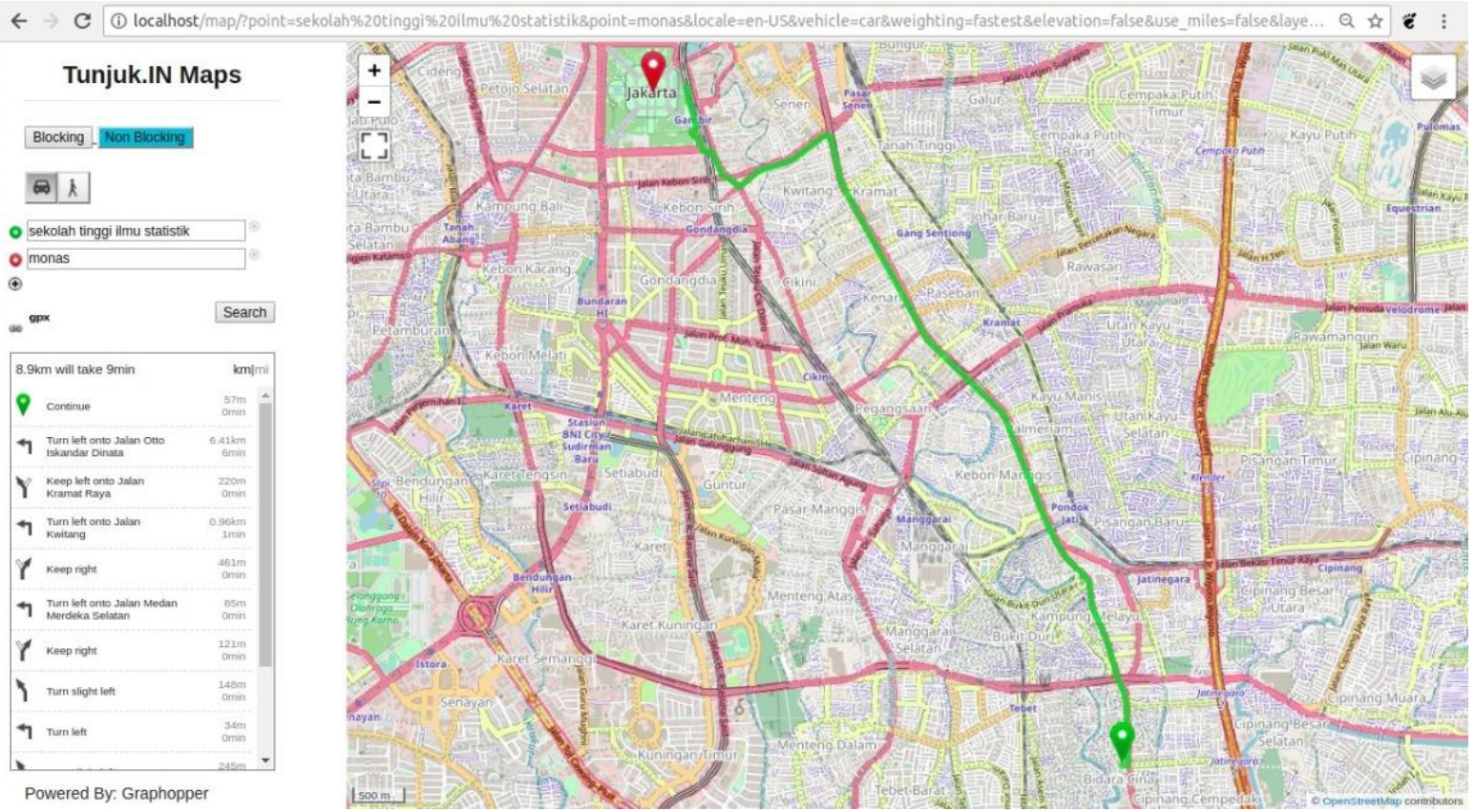

Figure 5. Example of generated regular routes without blocking

\subsection{Proposed Routes with Blocking Area Prone to Crime}

Based on the available historical crime data and user reported experience recorded in the database, our framework will provide the automatic safety routes which avoid crime hotspot area. Users are also able to select the travelling choices: by driving a car or by walking.

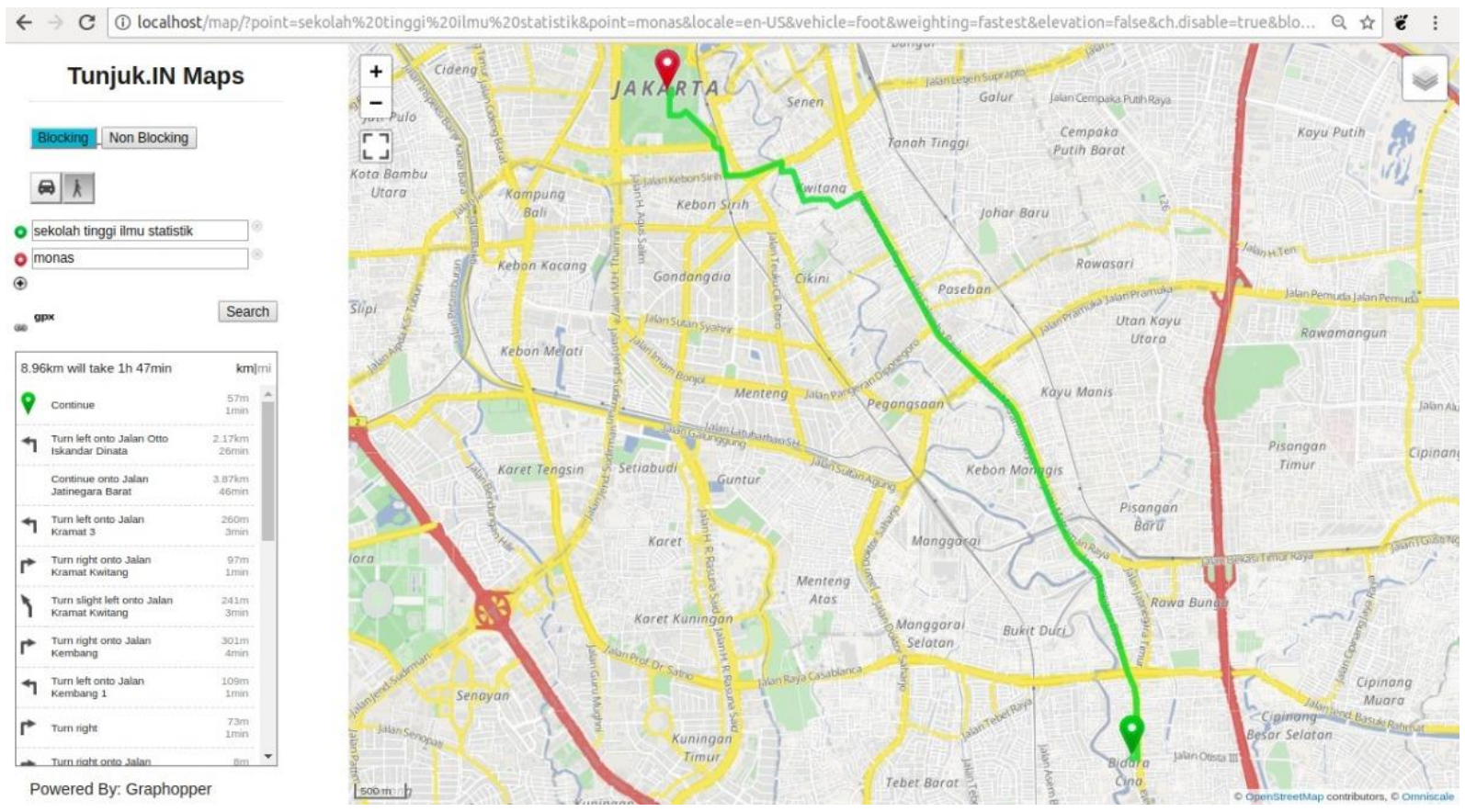

Figure 6. Example of recommended routes with blocking crime-prone areas 
With this method the user will get a safe experiences by recommended routes with blocking crime prone areas. In the others result, By choose blocking features showed a long route recommendation than regular route because automatically avoid the crime prone areas. It makes takes time on the road but have a safely trip.

\section{CONCLUSIONS}

In this paper, we propose an integrated web-based system using the crime hotspot area based on crime history from the local government agency, existing geotagged social media crime news and user reported data. The key result of the proposed personalized safety route recommender application is a personal navigation map that recommends the safest route to the user which bypass potential crime-prone areas. The additional benefit over other existing applications, such as Google Maps are the recommendation of blocking feature to avoids crime areas that match user reports and crime historical data.

Not only provides the comfortability in dealing with the safety issue, our framework is also still maintaining the effective advantage of current navigation applications that is minimizing the path from original location to the desired user destination. The potential benefit of our framework may be beneficial for many users such as women, children and elderly people.

\section{REFERENCES}

[1] Tong, Tingting; Yu, T. Edward, "Transportation and economic growth in China: A heterogeneous panel cointegration and causality analysis", Journal of Transport Geography, 73 (2018).

[2] Pindarwati, Atut, "Integrasi Area Rawan Kejahatan dalam Aplikasi Anjuran Rute Perjalanan Berbasis Peta Online Studi Kasus: Politeknik Statistika”,32 (2018).

[3] Google Play Store, "Maps - Navigate \& Explore, Version 10.20.1”, 9 July 2019.

[4] Brantingham P.L., Brantingham P.J., "Mapping crime for analytic purposes: location quotients, counts and rates: Crime Mapping and Crime Prevention. Eds DWeisburd, T McEwen. Criminal Justice Press, Monsey, NY". $263-288$ (1998)

[5] Wijayanto, A. W. \& Takdir. "Fighting cyber crime in email spamming: An evaluation of fuzzy clustering approach to classify spam messages" in 2014 International Conference on Information Technology Systems and Innovation (ICITSI) 19-24 (IEEE, 2014).

[6] Wijayanto, A. W., Purwarianti, A. \& Son, L. H, "Fuzzy geographically weighted clustering using artificial bee colony: An efficient geo-demographic analysis algorithm and applications to the analysis of crime behavior in population. Applied Intelligence" 44, 377-398 (2016).

[7] Domino Project, "Creating interactive crime maps with Folium" [WWW Document]. Data Sci. Blog Domino. URL https://blog.dominodatalab.com/creating-interactive-crime-maps-with-folium/ (2015).

[8] Kahle, D., Wickham, H, "ggmap: Spatial Visualization with ggplot2. R J.“5 (2013)

[9] White E.C, Bernstein D., Kornhauser A.L., "Some map matching algorithms for personal navigation assistants. Transportation Research Part C: Emerging Technologies", Volume 8, Issues 1-6, 91-108 (2000)

[10] Steinmann R., Krek A., Blaschke T., "Can Online Map-Based Applications Improve Citizen Participation?. In: Böhlen M., Gamper J., Polasek W., Wimmer M.A. (eds) E-Government: Towards Electronic Democracy. TCGOV 2005. Lecture Notes in Computer Science"., Springer, Berlin, Heidelberg , 3416 (2005)

[11] Khavak h, A., McDonough, W., Voloshin, O., Wang, Y., "Method and system for route calculation in a navigation application". US6678611B2." (2004)

[12] Khan Academy, "Contour maps" [WWW Document]. Khan Acad. URL https://www.khanacademy.org/math/multivariable-calculus/thinking-about-multivariable-function/ways-torepresent-multivariable-functions/a/contour-maps (accessed 6.3.18) (2018)

[13] Hu, Shunfu \& Dai, Ting., "Online map application development using google maps API, SQL database, and ASP.NET" International Journal of Information and Communication Technology Research. 3. (2013)

[14] DKI Jakarta, "Data Jumlah Kejahatan Pelanggaran Kamtibnas Menurut Jenis dan Kabupaten/Kota Administrasi di Provinsi DKI Jakarta" URL http://data.jakarta.go.id/dataset/data-jumlah-kejahatan-pelanggaran-kamtibnasmenurut-jenis-dan-kabupaten-kota-administrasi (2019) 
[15] Graphopper, "GraphHopper Directions API (1.0.0)", URL https://docs.graphhopper.com/ (accesed 25.7.19) (2019)

[16] Levy, S., Xiong, W., Belding, E., Wang, Y, W., "Safe Route: Learning to Navigate Streets Safety in an Urban Environment", ARXIV:1811.01147v1 (2018)

[17] Galbrun, E., Pelechrinis, K., Terzi, E., "Safe Navigation in Urban Envirnments”, UrbComp (2014) 